\title{
Skeletal muscle index is an independent predictor of early recurrence in non-obese colon cancer patients
}

\author{
Dagmar Schaffler-Schaden ${ }^{1}$ (D) C Christof Mittermair ${ }^{2,3} \cdot$ Theresa Birsak $^{2,3} \cdot$ Michael Weiss $^{2,3} \cdot$ Tobias Hell $^{4}$. \\ Gottfried Schaffler ${ }^{5}$ Helmut Weiss ${ }^{2,3}$
}

Received: 31 January 2020 / Accepted: 25 May 2020 / Published online: 5 June 2020

(C) The Author(s) 2020

\begin{abstract}
Purpose Progressive loss (sarcopenia) and fatty infiltration of muscle mass (myosteatosis) are well-established risk factors for an adverse clinical outcome in obese patients. Data concerning non-obese sarcopenic patients in oncologic surgery are scarce and heterogeneous. The aim of this study was to determine the impact of sarcopenia and myosteatosis in non-obese patients with cancer of the right colon on clinical outcome.

Methods This study comprised 85 patients with a $\mathrm{BMI}<30 \mathrm{~kg} / \mathrm{m}^{2}$, who underwent surgery for right colon cancer in a single center. Skeletal muscle area (SMA), visceral fat area (VFA), and myosteatosis were retrospectively assessed using preoperative abdominal CT images. Univariate und multivariate analysis was performed to evaluate the association between body composition, complications, and oncologic follow-up.

Results Traditional risk factors such as visceral fat $(p=0.8653)$, BMI $(p=0.8033)$, myosteatosis $(p=0.7705)$, and sarcopenia $(p=0.3359)$ failed to show any impact on postoperative complications or early recurrence. In our cohort, the skeletal muscle index (SMI) was the only significant predictor for early cancer recurrence $(p=0.0467)$.

Conclusion SMI is a significant prognostic factor for early cancer recurrence in non-obese colon cancer patients. Our study shows that conventional thresholds for sarcopenia and BMI do not seem to be reliable across various cohorts. Target prehabilitation programs could be useful to improve outcome after colorectal surgery.
\end{abstract}

Trial Registration DRKS00014655, www.apps.who.int/trialsearch

Keywords Sarcopenia $\cdot$ Skeletal muscle index $\cdot$ Prehabilitation $\cdot$ Colon cancer $\cdot$ Body composition

Dagmar Schaffler-Schaden

dagmar.schaffler@pmu.ac.at

Christof Mittermair

christof.mittermair@bbsalz.at

Theresa Birsak

theresa.birsak@alumni.pmu.ac.at

Michael Weiss

michael.weiss1@me.com

Tobias Hell

tobias.hell@uibk.ac.at

Gottfried Schaffler

gottfried.schaffler@bbsalz.at

Helmut Weiss

helmut.weiss@bbsalz.at
1 Institute of General Practice, Family Medicine and Preventive Medicine, Paracelsus Medical University, Strubergasse 21, 5020 Salzburg, Austria

2 Department of Surgery, St. John of God Hospital, Kajetanerplatz 1, 5020 Salzburg, Austria

3 Department of Surgery, St. John of God Teaching Hospital of Paracelsus Medical University, Kajetanerplatz 1, 5010 Salzburg, Austria

4 Department of Mathematics, University of Innsbruck, Technikerstrasse 13, 6020 Innsbruck, Austria

5 Department of Radiology and Nuclear Medicine, St. John of God Teaching Hospital of Paracelsus Medical University, Kajetanerplatz 1, 5010 Salzburg, Austria 


\section{Introduction}

Sarcopenia and obesity represent major public health problems in the aging population. Therapeutic and preventive strategies include physical exercise or nutritional concepts; however, to date, no evidence-based management recommendations exist. Sarcopenia is commonly defined as a progressive loss of skeletal muscle mass and functional strength. This muscle depletion is often accompanied by intra- and intermyocellular fatty infiltration (myosteatosis). Different methods have been introduced to determine these body composition parameters, such as physical performance tests or image analysis assessment [1]. Current literature appears contradictory due to various cut-off values, heterogeneous study populations, and definitions of body composition parameters in oncologic subjects. Sarcopenia and myosteatosis were identified as prognostic factors in various malignancies and are associated with longer hospital stays, increased toxicity of chemotherapy, as well as postoperative morbidity and mortality [2-4]. These adverse effects have also been demonstrated in patients with colorectal cancer (CRC) [2, 5-10]. On the other hand, a number of studies refer to obesity as a factor of higher morbidity and mortality in CRC patients [11-15]. The combination of sarcopenia, myosteatosis, and obesity seems to be a particularly unfavorable constellation. Since the prevalence of obesity and sarcopenia in industrial countries are increasing, many authors reported the adverse impact of sarcopenic obesity on clinical outcomes in several types of tumors $[4,16,17]$. However, the evidence is scarce so far to sufficiently demonstrate the effect of sarcopenia and myosteatosis in the non-obese colon cancer population.

The objective was to investigate the impact of body composition parameters on clinical outcome in a non-obese, homogeneous population with potentially curable colon cancer of the right colon.

\section{Materials and methods}

\section{Study population and setting}

Eighty-nine non-obese patients (BMI $<30 \mathrm{~kg} / \mathrm{m}^{2}$ ) with confirmed cancer of the right colon, who underwent elective surgery with curative intent between 2010 and 2016, were enrolled in the study. Eighty-five patients were included in the final analysis; the exclusion of 4 patients was due to incomplete follow-up data. The protocol differentiated patients with conventional open right colectomy (O-RC, $n=31)$ or minimally invasive right colectomy utilizing a transumbilical single-port approach (SIL-RC, $n=54$ ).

Patients were included if the following inclusion criteria were met: age $>18$ years, confirmed cancer of the right colon, and available preoperative abdominal CT scan (within 30 days before operation). Patients with solitary hepatic metastases had simultaneous removal and were found eligible for inclusion. Exclusion criteria were benign tumor, emergency surgery, recurrent disease, any $\mathrm{BMI} \geq 30 \mathrm{~kg} / \mathrm{m}^{2}$ or missing follow-up data/CT images.

Data of this cohort study was retrieved retrospectively from a prospectively collected electronic database and included demographic data, American Society of Anesthesiologists (ASA) grade, tumor site and TNM stage according to Union for International Cancer Control (UICC), tumor grade and vessel invasion, blood transfusion, diabetes mellitus, conversion rate, and length of hospital stay. Follow-up was performed according to current oncological guidelines for colorectal cancer. The primary endpoint was defined as any evidence of recurrent disease (locally or distant) within 1 year from the date of operation, and the secondary endpoint was intra- and postoperative complications. Complications were assessed according to the Clavien-Dindo system [18]; grade 3 or higher was considered major complications. Demographic parameters of patients and body composition characteristics are shown in Table 1.

\section{Surgical technique}

Patient management followed a modified enhanced recovery strategy protocol in all study patients. This protocol included thoracic epidural analgesia, avoidance of excess fluid administration and volume overload, a multimodal antiemetic approach, no drainage or nasogastric tube, early progressive mobilization and oral nutrition, early removal of epidural and urinary catheters, and opioid sparing analgesia.

The choice of surgical approach (open or SIL) depended upon the surgeons ' preference; all operations were performed by experienced surgeons. Open conventional surgery was performed in patients in supine position via a transverse right abdominal incision following the principles of complete mesocolic excision (CME) with dissection of the respective lymph node basin up to the trunk of Henle. Ileocolic anastomosis was established in a side-to-side stapler technique. Mesentery defects were reapproximated routinely. SIL procedures were performed using disposable devices (SILS-Port ${ }^{\mathrm{TM}}$, Medtronic, Dublin, Ireland; GelPort ${ }^{\mathrm{TM}}$, Applied Medical, Rancho Santa Margarita, USA; OctoPort ${ }^{\mathrm{TM}}$, DalimSurgNET, Frankenman Group, Seoul, Korea) at the umbilical site only. Additional trocars, other than this device, were not necessary in any patient. In all procedures, extra-long optical devices $\left(10 \mathrm{~mm}\right.$ diameter, $30^{\circ}$ optics $)$ were used. Additional instruments or suspension devices were used in all patients and delivered through the umbilical site to alleviate the exposure of the surgical field. CME and extended lymphadenectomy were carried out according to the open technique. 


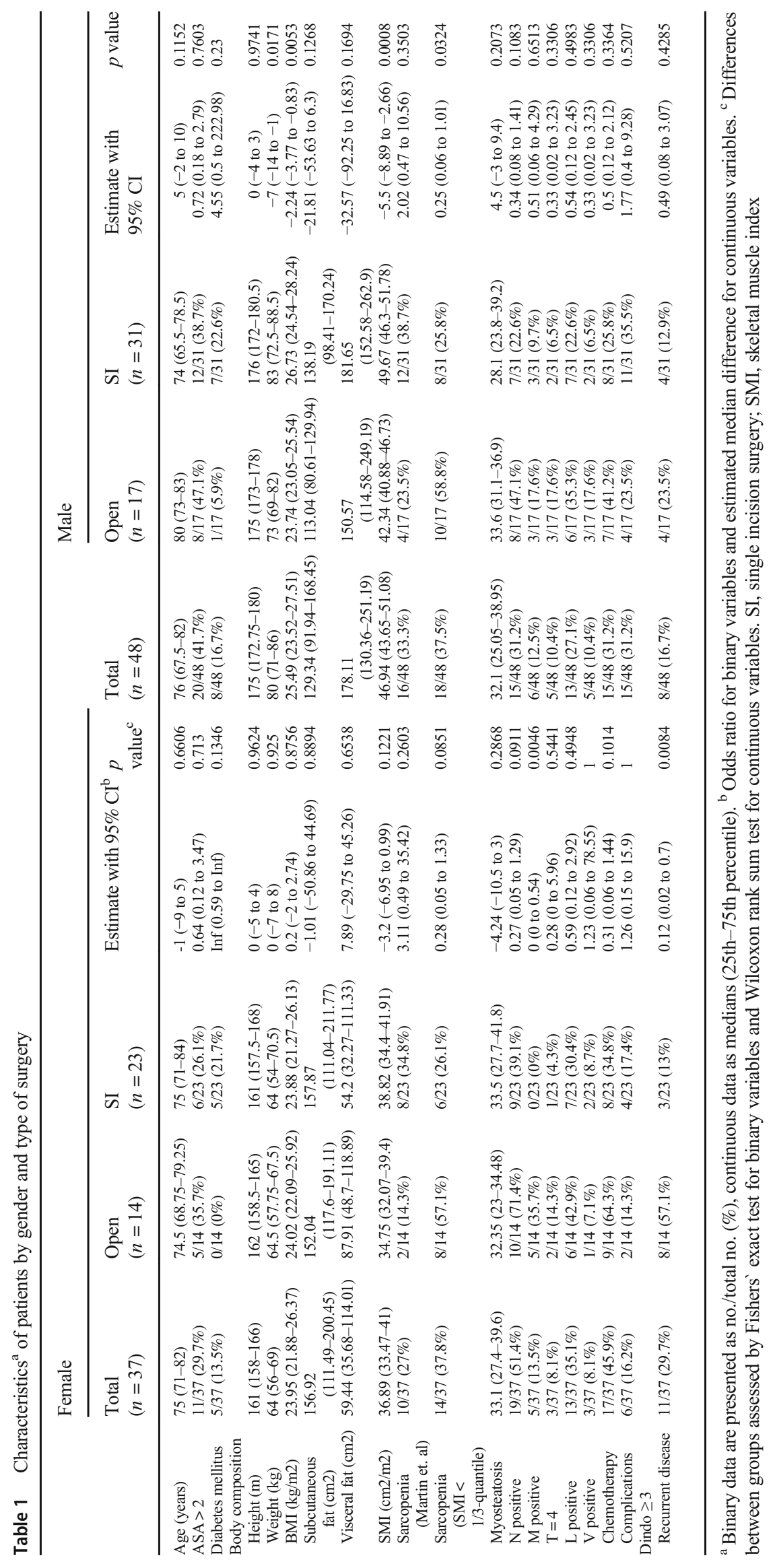




\section{Image analysis}

The assessment of body composition was performed by two independent investigators on preoperative routine $\mathrm{CT}$ scans, after individual training, who were blinded to the patients' identity. Scans with a strong deviation of values were checked by a senior radiologist. CT scans within 30 days prior surgery were considered suitable for examination. Contrast-enhanced CT images with 2.5-3-mm slice thickness $(100-130 \mathrm{kVp}$, and 150-300 mAS, Emotion 6 or Somatom Definition AS Siemens Healthcare GmbH, Erlangen) at the level of the third lumbar vertebra (L3) were retrieved from the Picture Archiving and Communication System (PACS@) of each patient. Image J (https://imagej.net/ImageJ) as an open source software was used to analyze each single image. Hounsfield Unit (HU) thresholds were used as previously described for skeletal muscle $(-29$ to +150$)$, for subcutaneous fat $(-190$ to $-30)$, and for visceral fat tissue ( -150 to -50$)$ [19]. Muscle area included psoas muscle, rectus abdominis, quadratus lumborum, erector spinae, abdominal lateral, and oblique muscle. Mean muscle attenuation (HU) representing myosteatosis was assessed at Level L3. The value for the skeletal muscle area was normalized for height $\left(\mathrm{m}^{2}\right)$ to create the skeletal muscle index (SMI, $\mathrm{cm}^{2} / \mathrm{m}^{2}$ ).

Sarcopenia was defined according to gender and BMI categories (BMI 20.0-29.9 kg/m²) as published previously [20]. Additionally, with respect to regional variations, the lowest sex-specific quartile of SMI within the study population was classified as sarcopenia for comparison.

\section{Statistical analysis}

The threshold for statistical significance was considered at a $p$ value $<0.05$; all tests were two-sided. Potential risk factors for complications were investigated using univariate analysis, namely, Fisher's exact test, Chi-square tests, the Wilcoxon rank sum test, the Wilcoxon signed rank test, the KruskalWallis test, and logistic univariate regression adjusted for gender in case of body composition parameters. Cox hazards regression stratified by gender for body composition parameters was performed for tumor recurrence. Amendatory, multivariate Cox hazards regression analysis was also conducted with significant univariate predictors for tumor recurrence and incorporating different treatment groups (open versus singleport laparoscopic). The statistical analyses were conducted using the software R (version 3.5.3; http://www.r-project.org).

\section{Results}

Thirty-one patients underwent open resection, and 54 patients SIL surgery. The surgical procedure was completed in all patients. The conversion rate was 5.5\% (3/54). Reasons for conversion were tumor size and adhesions in two cases and adhesions in one case. No intraoperative complications were observed. Fifteen major complications $(17.6 \%$, ClavienDindo $\geq 3$ ) requiring further intervention occurred; for further details, see Table 2 . The overall rate of anastomotic leakage was 6/85 (7\%); one occurred in the O-RC group (handsewn), and the remaining five occurred in the SIL-RC group (all stapled: four intracorporeally, one extracorporeally).

The prevalences of sarcopenia in total were $30.6 \%$ and $32.9 \%$ respectively, depending on the assessment method; mean value for myosteatosis (HU) in total was 32.3 (see Table 1). Thirty-day mortality was zero in the entire cohort. The postoperative oncologic follow-up revealed nine (29\%) patients with recurrent disease in the O-RC group, and three patients in the SIL-RC group.

In our study population, none of the traditional body composition parameters (BMI, subcutaneous fat tissue, visceral fat tissue) or myosteatosis had a significant impact on complications or tumor recurrence in univariate or multivariate calculation. With regard to muscle depletion, all parameters were determined by univariate and multivariate analysis. See an overview of results in Table 3. SMI was the only prognostic relevant factor for tumorfree survival in univariate analysis, but was not associated with postoperative complications. In multivariate analysis, the SMI was not significant which can be contributed to the sample size. Prevalent metastatic disease was the only significant negative oncologic predictor. Minimizing the surgical trauma by means of SIL could not show any significant impact during the oncologic follow-up. The risk for 1-year-tumor recurrence was significantly higher for patients who underwent open surgery as compared with single incision $(p=0.0241)$. However, the rate of patients with metastasis (M-positive) was significantly higher in the open surgery group as compared with single incision (8/31 (25.8\%) vs. $3 / 54(5.5 \%), p=0.0151)$. When adjusting the groups for $\mathrm{M}$ positive, the risk for 1-year-recurrence is comparable ( $p=0.6478$ ), (see Fig. 1).

Table 2 Overview of major and minor complications

\begin{tabular}{|c|c|c|}
\hline Complications & Dindo $\geq 3$ & Data \\
\hline Anastomotic leakage & & $6(7 \%)$ \\
\hline Hemorrhage & & $4(4.7 \%)$ \\
\hline Fascia dehiscence & & $3(3.5 \%)$ \\
\hline Ileus & & 1 \\
\hline \multirow[t]{2}{*}{ Abscess } & & 1 \\
\hline & Dindo $<3$ & \\
\hline Cardiac decompensation & & 1 \\
\hline Hematoma/Abscess & & 3 \\
\hline Pneumonia & & 2 \\
\hline
\end{tabular}




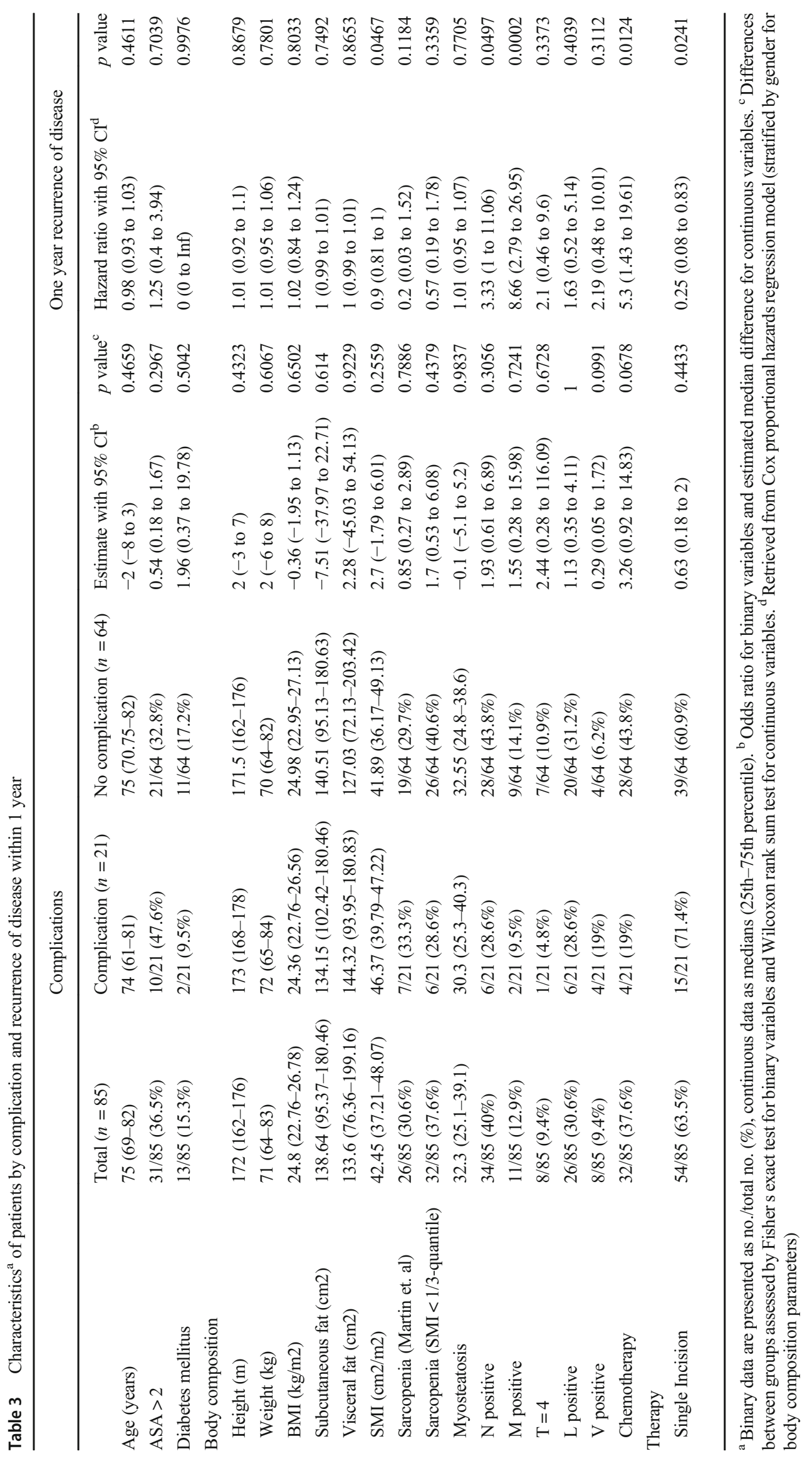


Fig. 1 Hazard ratios retrieved from Cox proportional harzards model for survival stratified by gender. Depicted are effect sizes (log hazard ratio); provided are hazard ratios with $95 \%$ CIs and corresponding $p$ values.

Adjusting for $\mathrm{M}$ positive, the risk for 1-year-recurrence is comparable (Hazard ratio 0.4 (2.5 to 6.39), $p=0.6478)$ in the open and laparoscopic group

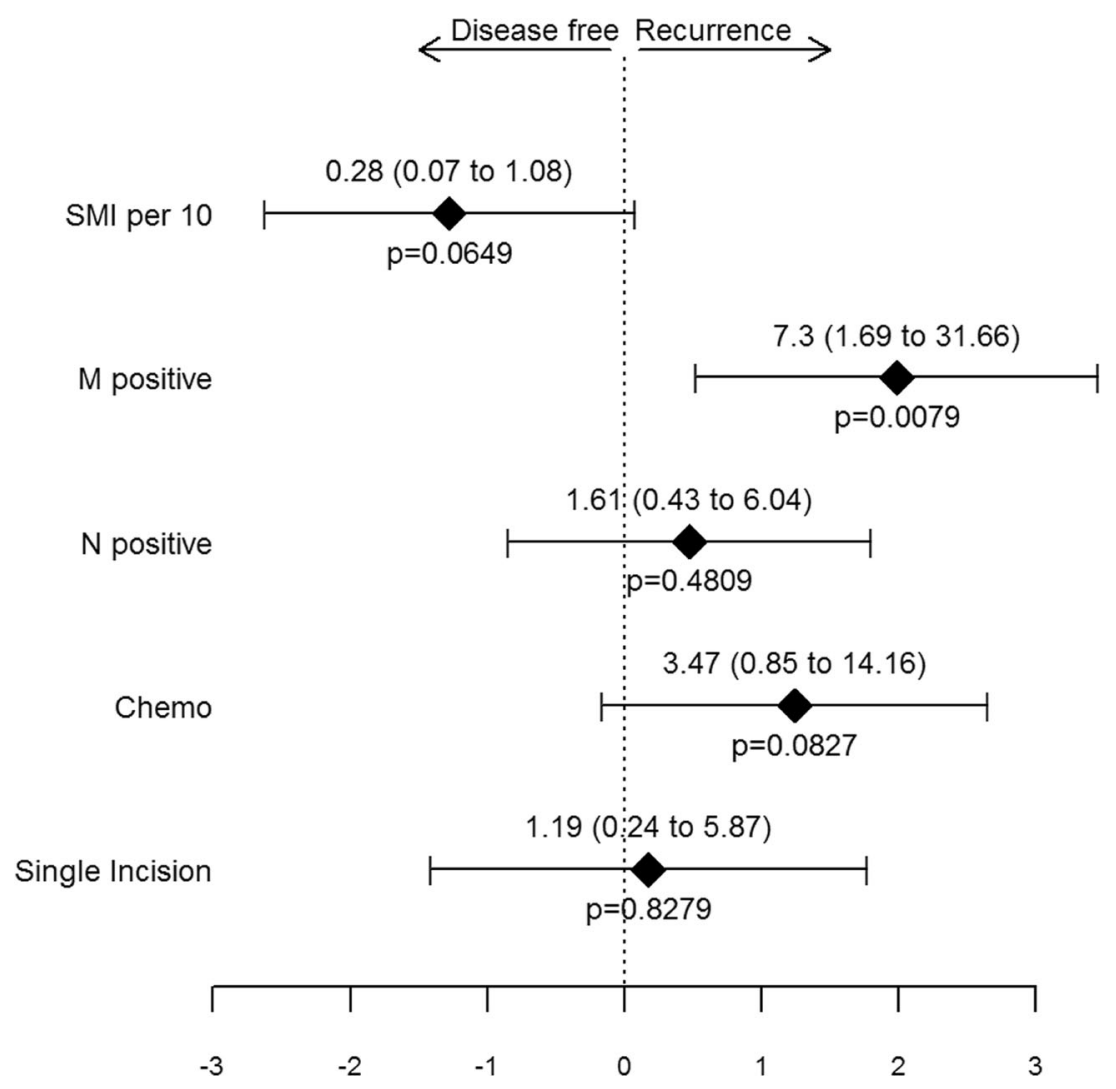

thresholds have been reported previously [23, 27]. Some authors observed a higher prevalence of postoperative complications in Asian sarcopenic patients with non-metastatic CRC [28]. Regarding several recently published meta-analyses and systematic reviews, it can be determined that a variety of body composition assessment methods, thresholds, and study populations were included. Sun et al. focused on patients with non-metastatic CRC indicating that sarcopenia is a risk factor for postoperative morbidity and mortality. This meta-analysis included six studies from Asia [28]. The reported prevalence of sarcopenia varies between 5 and $79 \%$, depending on the population $[2,29]$. Thresholds for one ethnic group are probably not applicable for other groups. Sarcopenia was observed in patients with any BMI and body weight [30], (see Fig. 2). BMI therefore seems not suitable as a predictor for surgical complications as shown in patients with advanced rectal cancer [31]. Obesity combined with muscle depletion (sarcopenic obesity) seems to be a particularly unfavorable condition, as it is linked to a higher morbidity and mortality in patients after cancer surgery [16, 24, 32]. Regarding sarcopenic and visceral obesity, various definitions exist as well [17, 33, 34]. Apparently, results are often depending on cut-off levels, assessment methods, and definitions of body composition thresholds. The positive impact of (conventional) laparoscopic surgery on sarcopenic patients has been confirmed, although evidence for the impact of surgical approach (open vs. laparoscopic) related to body composition parameters is 

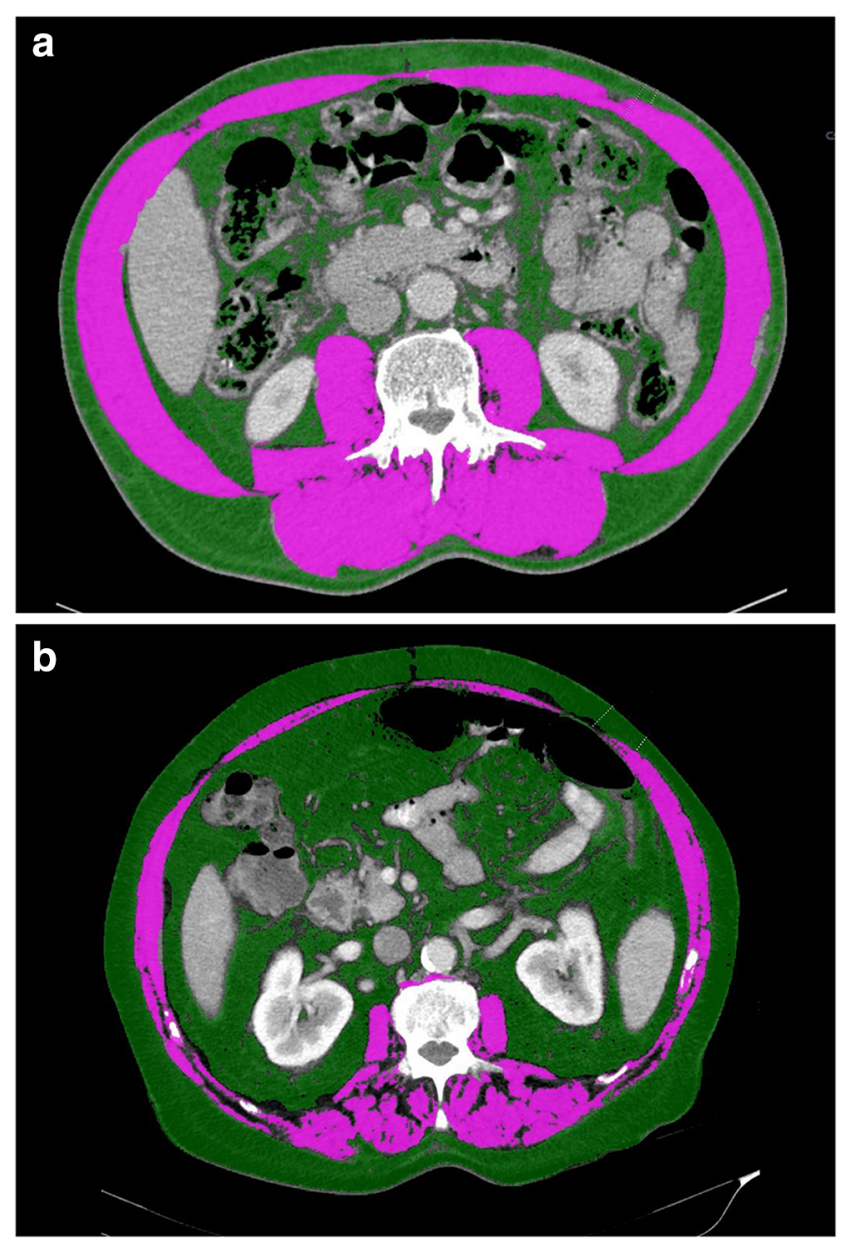

Fig. 2 Abdominal CT images of patients with identical BMI $(28.7 \mathrm{~kg}$ / $\mathrm{m}^{2}$ ), patient A with a SMI of $67.8 \mathrm{~cm}^{2} / \mathrm{m}^{2}$, and patient B with a SMI $35.3 \mathrm{~cm}^{2} / \mathrm{m}^{2}$; green: subcutaneous and visceral fat tissue, pink: skeletal muscle tissue

scarce $[17,35,36]$.The advantages of minimally invasive surgery in colorectal cancer regarding blood loss, length of hospital stay, wound pain, and postoperative complications have been reported in large randomized controlled trials [37]. Due to the small sample size and heterogeneity in the two groups (patients in the open group had more often advanced disease), it was not possible to explore the impact of surgical approach on the clinical outcome in our cohort. Prevention and therapy of sarcopenia and its known adverse effects are currently the major focus of many research projects. Targeted concepts with short-term resistance training and nutritional supplementation have shown promising results in the treatment of sarcopenia [38-40]. Especially physical activity seems to have a positive impact on surgical outcome as a randomizedcontrolled trial proved - although the preoperative timeframe is usually short [41]. A recent review reported an improved 5year disease-free survival for colorectal cancer patients undergoing prehabilitation, at least for the subgroup with stage III cancer. No benefit was observed concerning the overall survival [42]. However, there is no evidence regarding which patients will benefit most from an adapted preoperative nutrition assessment and physical exercise training prior to surgery [43]. Nevertheless, preoperative identification of patients with higher operative risk is essential to avoid a complicated course with serious impact on quality of life.

This study has several limitations. Interobserver variability was not assessed for the image evaluation. Furthermore, functional muscle assessment was not included and no long-term outcomes were reported. As we focused on a non-obese population with the same cancer localization, the sample size was limited. The strength of this study is the ethnically homogeneous study population with potentially curable colon cancer located in the right colon, all operated in a single center according to a standardized open or laparoscopic procedure.

In conclusion, a reduced SMI is an important predictive factor for early recurrence of colon cancer. Heterogeneity of assessment methods, study populations, and threshold variations of body composition parameters currently hamper comparability of study results in daily surgical routine. Absolute thresholds for sarcopenia do not seem to be reliable in different settings. The preoperative identification of patients at risk for an unfavorable postoperative course seems to be an important issue. The results of this study should be interpreted with caution, as our cohort did not undergo a specific preoperative nutrition or training program. Well-designed randomized studies could probably help to show the impact of individually tailored prehabilitation programs on the postoperative clinical course in sarcopenic patients.

Acknowledgments We thank Prof. Erich Sorantin, MD, University Clinic of Radiology, Medical University Graz, and Isabella Wallner, Bsc, St.John of God Hospital, Department of Radiology and Nuclear Medicine, Salzburg, for their support in graphic image processing.

Authors' contributions Study conception and design: DSS, CM, HW, GS; Acquisition of data: DSS, CM, TB, MW; Analysis and interpretation of data: CM, HW, TH; Drafting of manuscript: DSS, CM, HW; Critical revision of manuscript: all

Funding Information Open access funding provided by Paracelsus Medical University.

\section{Compliance with ethical standards}

Conflict of interest The authors declare that they have no conflict of interest.

Ethical approval This study has obtained ethical approval from the Ethics committee (Ref. ID 415-E/2236/2-2017) of Salzburg county.

Informed consent All patients gave informed consent prior to surgery and the study was performed in accordance with the ethical standards as laid down in the 1964 Declaration of Helsinki and its later amendments. 
Standards of reporting This work has been reported in line with the STROBE criteria.

Open Access This article is licensed under a Creative Commons Attribution 4.0 International License, which permits use, sharing, adaptation, distribution and reproduction in any medium or format, as long as you give appropriate credit to the original author(s) and the source, provide a link to the Creative Commons licence, and indicate if changes were made. The images or other third party material in this article are included in the article's Creative Commons licence, unless indicated otherwise in a credit line to the material. If material is not included in the article's Creative Commons licence and your intended use is not permitted by statutory regulation or exceeds the permitted use, you will need to obtain permission directly from the copyright holder. To view a copy of this licence, visit http://creativecommons.org/licenses/by/4.0/.

\section{References}

1. Bahat G, Tufan A, Kilic C, Karan MA, Cruz-Jentoft AJ (2018) Prevalence of sarcopenia and its components in communitydwelling outpatient older adults and their relation with functionality. Aging Male:1-7. https://doi.org/10.1080/13685538.2018. 1511976

2. Levolger S, van Vugt JL, de Bruin RW, IJ JN (2015) Systematic review of sarcopenia in patients operated on for gastrointestinal and hepatopancreatobiliary malignancies. Br J Surg 102(12):14481458. https://doi.org/10.1002/bjs.9893

3. Prado CM, Baracos VE, McCargar LJ, Mourtzakis M, Mulder KE, Reiman T, Butts CA, Scarfe AG, Sawyer MB (2007) Body composition as an independent determinant of 5-fluorouracil-based chemotherapy toxicity. Clin Cancer Res 13(11):3264-3268. https:// doi.org/10.1158/1078-0432.CCR-06-3067

4. Boer BC, de Graaff F, Brusse-Keizer M, Bouman DE, Slump CH, Slee-Valentijn M, Klaase JM (2016) Skeletal muscle mass and quality as risk factors for postoperative outcome after open colon resection for cancer. Int J Color Dis 31(6):1117-1124. https://doi. org/10.1007/s00384-016-2538-1

5. Huang DD, Wang SL, Zhuang CL, Zheng BS, Lu JX, Chen FF, Zhou CJ, Shen X, Yu Z (2015) Sarcopenia, as defined by low muscle mass, strength and physical performance, predicts complications after surgery for colorectal cancer. Color Dis 17(11):O256O264. https://doi.org/10.1111/codi.13067

6. Lieffers JR, Bathe OF, Fassbender K, Winget M, Baracos VE (2012) Sarcopenia is associated with postoperative infection and delayed recovery from colorectal cancer resection surgery. Br J Cancer 107(6):931-936. https://doi.org/10.1038/bjc.2012.350

7. Wagner D, DeMarco MM, Amini N, Buttner S, Segev D, Gani F, Pawlik TM (2016) Role of frailty and sarcopenia in predicting outcomes among patients undergoing gastrointestinal surgery. World J Gastrointest Surg 8(1):27-40. https://doi.org/10.4240/ wjgs.v8.i1.27

8. Reisinger KW, van Vugt JL, Tegels JJ, Snijders C, Hulsewe KW, Hoofwijk AG, Stoot JH, Von Meyenfeldt MF, Beets GL, Derikx JP, Poeze M (2015) Functional compromise reflected by sarcopenia, frailty, and nutritional depletion predicts adverse postoperative outcome after colorectal cancer surgery. Ann Surg 261(2):345-352. https://doi.org/10.1097/SLA.0000000000000628

9. Miyamoto Y, Baba Y, Sakamoto Y, Ohuchi M, Tokunaga R, Kurashige J, Hiyoshi Y, Iwagami S, Yoshida N, Yoshida M, Watanabe M, Baba H (2015) Sarcopenia is a negative prognostic factor after curative resection of colorectal Cancer. Ann Surg Oncol 22(8):2663-2668. https://doi.org/10.1245/s10434-014-4281-6
10. Malietzis G, Johns N, Al-Hassi HO, Knight SC, Kennedy RH, Fearon KC, Aziz O, Jenkins JT (2016) Low muscularity and myosteatosis is related to the host systemic inflammatory response in patients undergoing surgery for colorectal cancer. Ann Surg 263(2):320-325. https://doi.org/10.1097/SLA.0000000000001113

11. Doleman B, Mills KT, Lim S, Zelhart MD, Gagliardi G (2016) Body mass index and colorectal cancer prognosis: a systematic review and meta-analysis. Tech Coloproctol 20(8):517-535. https://doi.org/10.1007/s10151-016-1498-3

12. Qiu Y, Liu Q, Chen G, Wang W, Peng K, Xiao W, Yang H (2016) Outcome of rectal cancer surgery in obese and nonobese patients: a meta-analysis. World J Surg Oncol 14(1):23. https://doi.org/10. 1186/s12957-016-0775-y

13. Ma Y, Yang Y, Wang F, Zhang P, Shi C, Zou Y, Qin H (2013) Obesity and risk of colorectal cancer: a systematic review of prospective studies. PLoS One 8(1):e53916. https://doi.org/10.1371/ journal.pone. 0053916

14. Cakir H, Heus C, van der Ploeg TJ, Houdijk AP (2015) Visceral obesity determined by CT scan and outcomes after colorectal surgery; a systematic review and meta-analysis. Int J Color Dis 30(7): 875-882. https://doi.org/10.1007/s00384-015-2174-1

15. Heus C, Bakker N, Verduin WM, Doodeman HJ, Houdijk APJ (2019) Impact of body composition on surgical outcome in rectal cancer patients, a retrospective cohort study. World J Surg 43(5): 1370-1376. https://doi.org/10.1007/s00268-019-04925-z

16. Pecorelli N, Capretti G, Sandini M, Damascelli A, Cristel G, De Cobelli F, Gianotti L, Zerbi A, Braga M (2017) Impact of Sarcopenic obesity on failure to rescue from major complications following pancreaticoduodenectomy for cancer: results from a multicenter study. Ann Surg Oncol 25:308-317. https://doi.org/10. 1245/s10434-017-6216-5

17. Chen WZ, Chen XD, Ma LL, Zhang FM, Lin J, Zhuang CL, Yu Z, Chen XL, Chen XX (2018) Impact of visceral obesity and sarcopenia on short-term outcomes after colorectal cancer surgery. Dig Dis Sci 63(6):1620-1630. https://doi.org/10.1007/s10620-0185019-2

18. Clavien PA, Barkun J, de Oliveira ML, Vauthey JN, Dindo D, Schulick RD, de Santibanes E, Pekolj J, Slankamenac K, Bassi C, Graf R, Vonlanthen R, Padbury R, Cameron JL, Makuuchi M (2009) The Clavien-Dindo classification of surgical complications: five-year experience. Ann Surg 250(2):187-196. https://doi.org/10. 1097/SLA.0b013e3181b13ca2

19. Mourtzakis M, Prado CM, Lieffers JR, Reiman T, McCargar LJ, Baracos VE (2008) A practical and precise approach to quantification of body composition in cancer patients using computed tomography images acquired during routine care. Appl Physiol Nutr Metab 33(5):997-1006. https://doi.org/10.1139/H08-075

20. Martin L, Birdsell L, Macdonald N, Reiman T, Clandinin MT, McCargar LJ, Murphy R, Ghosh S, Sawyer MB, Baracos VE (2013) Cancer cachexia in the age of obesity: skeletal muscle depletion is a powerful prognostic factor, independent of body mass index. J Clin Oncol 31(12):1539-1547. https://doi.org/10.1200/ JCO.2012.45.2722

21. Black D, Mackay C, Ramsay G, Hamoodi Z, Nanthakumaran S, Park KGM, Loudon MA, Richards CH (2017) Prognostic value of computed tomography: measured parameters of body composition in primary operable gastrointestinal cancers. Ann Surg Oncol 24(8): 2241-2251. https://doi.org/10.1245/s10434-017-5829-Z

22. Masanés F, Rojano I, Luque X, Salvà A, Serra-Rexach JA, Artaza I, Formiga F, Cuesta F, López Soto A, Ruiz D, Cruz-Jentoft AJ (2017) Cut-off points for muscle mass - not grip strength or gait speed - determine variations in sarcopenia prevalence. J Nutr Health Aging 21(7):825-829. https://doi.org/10.1007/s12603-016-0844-5

23. Simonsen C, de Heer P, Bjerre ED, Suetta C, Hojman P, Pedersen BK, Svendsen LB, Christensen JF (2018) Sarcopenia and postoperative complication risk in gastrointestinal surgical oncology: a 
meta-analysis. Ann Surg 268(1):58-69. https://doi.org/10.1097/ SLA.0000000000002679

24. Malietzis G, Currie AC, Athanasiou T, Johns N, Anyamene N, Glynne-Jones R, Kennedy RH, Fearon KC, Jenkins JT (2016) Influence of body composition profile on outcomes following colorectal cancer surgery. Br J Surg 103(5):572-580. https://doi.org/ $10.1002 /$ bjs. 10075

25. Nakanishi R, Oki E, Sasaki S, Hirose K, Jogo T, Edahiro K, Korehisa S, Taniguchi D, Kudo K, Kurashige J, Sugiyama M, Nakashima Y, Ohgaki K, Saeki H, Maehara Y (2018) Sarcopenia is an independent predictor of complications after colorectal cancer surgery. Surg Today 48(2):151-157. https://doi.org/10.1007/ s00595-017-1564-0

26. Mintziras I, Miligkos M, Wächter S, Manoharan J, Maurer E, Bartsch DK (2018) Sarcopenia and sarcopenic obesity are significantly associated with poorer overall survival in patients with pancreatic cancer: systematic review and meta-analysis. Int J Surg 59: 19-26. https://doi.org/10.1016/j.ijsu.2018.09.014

27. Jones K, Gordon-Weeks A, Coleman C, Silva M (2017) Radiologically determined sarcopenia predicts morbidity and mortality following abdominal surgery: a systematic review and metaanalysis. World J Surg 41(9):2266-2279. https://doi.org/10.1007/ s00268-017-3999-2

28. Sun G, Li Y, Peng Y, Lu D, Zhang F, Cui X, Zhang Q, Li Z (2018) Can sarcopenia be a predictor of prognosis for patients with nonmetastatic colorectal cancer? A systematic review and meta-analysis. Int J Color Dis 33:1419-1427. https://doi.org/10.1007/s00384018-3128-1

29. Malietzis G, Aziz O, Bagnall NM, Johns N, Fearon KC, Jenkins JT (2015) The role of body composition evaluation by computerized tomography in determining colorectal cancer treatment outcomes: a systematic review. Eur J Surg Oncol 41(2):186-196. https://doi. org/10.1016/j.ejso.2014.10.056

30. Thoresen L, Frykholm G, Lydersen S, Ulveland H, Baracos V, Prado CM, Birdsell L, Falkmer U (2013) Nutritional status, cachexia and survival in patients with advanced colorectal carcinoma. Different assessment criteria for nutritional status provide unequal results. Clin Nutr 32(1):65-72. https://doi.org/10.1016/j.clnu.2012. 05.009

31. Jochum SB, Kistner M, Wood EH, Hoscheit M, Nowak L, Poirier J, Eberhardt JM, Saclarides TJ, Hayden DM (2019) Is sarcopenia a better predictor of complications than body mass index? Sarcopenia and surgical outcomes in patients with rectal cancer. Color Dis 21: 1372-1378. https://doi.org/10.1111/codi.14751

32. Lou N, Chi CH, Chen XD, Zhou CJ, Wang SL, Zhuang CL, Shen X (2017) Sarcopenia in overweight and obese patients is a predictive factor for postoperative complication in gastric cancer: a prospective study. Eur J Surg Oncol 43(1):188-195. https://doi.org/10. 1016/j.ejso.2016.09.006

33. Pecorelli N, Carrara G, De Cobelli F, Cristel G, Damascelli A, Balzano G, Beretta L, Braga M (2016) Effect of sarcopenia and visceral obesity on mortality and pancreatic fistula following pancreatic cancer surgery. Br J Surg 103(4):434-442. https://doi.org/ 10.1002/bjs. 10063

34. Mei KL, Batsis JA, Mills JB, Holubar SD (2016) Sarcopenia and sarcopenic obesity: do they predict inferior oncologic outcomes after gastrointestinal cancer surgery? Perioper Med (Lond) 5:30. https://doi.org/10.1186/s13741-016-0052-1

35. Pedziwiatr M, Pisarska M, Major P, Grochowska A, Matlok M, Przeczek K, Stefura T, Budzynski A, Klek S (2016) Laparoscopic colorectal cancer surgery combined with enhanced recovery after surgery protocol (ERAS) reduces the negative impact of sarcopenia on short-term outcomes. Eur J Surg Oncol 42(6):779-787. https:// doi.org/10.1016/j.ejso.2016.03.037

36. Ouchi A, Asano M, Aono K, Watanabe T, Oya S (2016) Laparoscopic colorectal resection in patients with sarcopenia: a retrospective case-control study. J Laparoendosc Adv Surg Tech A 26(5):366-370. https://doi.org/10.1089/lap.2015.0494

37. Green BL, Marshall HC, Collinson F, Quirke P, Guillou P, Jayne DG, Brown JM (2013) Long-term follow-up of the Medical Research Council CLASICC trial of conventional versus laparoscopically assisted resection in colorectal cancer. Br J Surg 100(1):75-82. https://doi.org/10.1002/bjs.8945

38. Piraux E, Caty G, Reychler G (2018) Effects of preoperative combined aerobic and resistance exercise training in cancer patients undergoing tumour resection surgery: a systematic review of randomised trials. Surg Oncol 27(3):584-594. https://doi.org/10. 1016/j.suronc.2018.07.007

39. Minnella EM, Carli F (2018) Prehabilitation and functional recovery for colorectal cancer patients. Eur J Surg Oncol 44(7):919-926. https://doi.org/10.1016/j.ejso.2018.04.016

40. Walcott-Sapp S, Billingsley KG (2018) Preoperative optimization for major hepatic resection. Langenbeck's Arch Surg 403(1):23-35. https://doi.org/10.1007/s00423-017-1638-x

41. Barberan-Garcia A, Ubré M, Roca J, Lacy AM, Burgos F, Risco R, Momblán D, Balust J, Blanco I, Martínez-Pallí G (2018) Personalised Prehabilitation in high-risk patients undergoing elective major abdominal surgery: a randomized blinded controlled trial. Ann Surg 267(1):50-56. https://doi.org/10.1097/SLA. 0000000000002293

42. Trépanier M, Minnella EM, Paradis T, Awasthi R, Kaneva P, Schwartzman K, Carli F, Fried GM, Feldman LS, Lee L (2019) Improved disease-free survival after prehabilitation for colorectal cancer surgery. Ann Surg 270(3):493-501. https://doi.org/10.1097/ SLA.0000000000003465

43. Hijazi Y, Gondal U, Aziz O (2017) A systematic review of prehabilitation programs in abdominal cancer surgery. Int J Surg 39:156-162. https://doi.org/10.1016/j.ijsu.2017.01.111

Publisher's note Springer Nature remains neutral with regard to jurisdictional claims in published maps and institutional affiliations. 